\title{
Philippe Desan, Portraits à l'essai. Iconographie de Montaigne
}

Concetta Cavallini

\section{(2) OpenEdition}

1 Journals

\section{Édition électronique}

URL : http://journals.openedition.org/studifrancesi/9487

DOI : 10.4000/studifrancesi.9487

ISSN : 2427-5856

Éditeur

Rosenberg \& Sellier

\section{Édition imprimée}

Date de publication : 1 décembre 2007

Pagination : 643-644

ISSN : 0039-2944

\section{Référence électronique}

Concetta Cavallini, «Philippe Desan, Portraits à l'essai. Iconographie de Montaigne », Studi Francesi [En ligne], 153 (LI | III) | 2007, mis en ligne le 30 novembre 2015, consulté le 08 janvier 2021. URL : http:// journals.openedition.org/studifrancesi/9487 ; DOI : https://doi.org/10.4000/studifrancesi.9487

Ce document a été généré automatiquement le 8 janvier 2021.

\section{(c) $(1) \&$}

Studi Francesi è distribuita con Licenza Creative Commons Attribuzione - Non commerciale - Non opere derivate 4.0 Internazionale. 


\title{
Philippe Desan, Portraits à l'essai. Iconographie de Montaigne
}

\author{
Concetta Cavallini
}

\section{RÉFÉRENCE}

PHILIPPE DESAN, Portraits à l'essai. Iconographie de Montaigne, Paris, Champion, 2007, pp. 349.

1 Pourquoi une iconographie de Montaigne? Parce que Montaigne est bien un de ces auteurs qui se donnent, à travers leur œuvre, complètement à leur public. Chacun de ses lecteurs, des spécialistes qui se sont occupés de lui, a voulu interpréter ses paroles et, au point de vue iconographique, a voulu construire une image de lui. Ce n'est peutêtre pas le vrai Montaigne qui est au centre de l'intérêt de ses lecteurs. Ce qui importe est sa capacité de susciter la curiosité d'hommes et de spécialistes durant quatre siècles; c'est sa flexibilité, son adaptabilité aux époques et aux goûts qui changent. Montaigne a toujours été actuel.

2 À ce jour, ce livre imposant de 350 pages illustrées est ce qu'on connaît de plus complet et de plus détaillé sur les images de Montaigne. La présentation de l'iconographie de Montaigne est précédée par un essai Portraits d'un gentilhomme voyageur (pp. 11-46) qui met en évidence le fait que les différentes reproductions de Montaigne ne font que renforcer l'«image changeante» (p. 13) de l'essayiste telle qu'elle ressort des Essais, ainsi que son identité constamment en mouvement, pour reprendre l'expression de Jean Starobinski. Le mouvement de l'homme Montaigne et le 'mouvement' des reproductions de Montaigne reflètent aussi l'évolution des styles de l'art du portrait. «Montaigne est aussi une histoire de styles, mais que serait un style sans une technique?», se demande l'auteur à la fin d'une «Remarque sur les techniques» (pp. 47-48) qui précède la présentation du catalogue raisonné des effigies de Montaigne.

3 Le choix de présentation est clair. Les Peintures et dessins, plus nombreux, sont présentés en premier (pp. 49-138), et comptent 80 numéros; suivent les Gravures et lithographies (pp. 139-275) avec 204 numéros, pour terminer avec les Sculptures, monuments, objets et 
médailles (pp. 277-324), avec 43 entrées. L'ouvrage se présente comme absolument scrupuleux dans la description des diverses techniques artistiques utilisées et dans la datation et la reconstruction de l'histoire des reproductions.

4 Chaque entrée dans ce catalogue raisonné est structurée d'après la même typologie: identification de la reproduction (portrait, lithographie, gravure, etc.), auteur (si son nom est connu), date de réalisation de l'œuvre, description technique, localisation de l'œuvre. Nous trouvons ensuite l'illustration, suivie par un commentaire sur l'histoire de la reproduction présentée, enrichie de données biographiques sur son auteur et d'une bibliographie en note qui rend compte de commentaires éventuels sur cette reproduction de la part de spécialistes de Montaigne pendant les siècles. Chaque numéro du catalogue rappelle aussi, par des renvois, les liens de typologie qui existent entre les différentes reproductions.

Comme les catalogues contenus dans les «Annexes» le prouvent, on peut repérer des 'familles' au sein des reproductions: outre la tradition des «Bustes de Montaigne» (p. 339), il y a aussi les «Montaigne chef nu» (p. 340) et les «Montaigne au chapeau» (p. 341), sans compter la tradition prolifique, surtout à l'époque romantique, des portraits et des gravures de «Montaigne visitant le Tasse» (pp. 342-343) et des «Médailles de Montaigne» (p. 344). En outre, comme l'«Index des artistes» (pp. 345-349) le prouve, bien des artistes cités sont responsables d'une ou plusieurs œuvres, comme Chéreau le Jeune, auteur de deux portraits de Montaigne gravés en 1723 et en 1725 ou Marie Payen, fille du célèbre montaigniste, qui réalisa cinq portraits, trois huiles en 1841 (fiche n. 49), 1843 (fiche n. 51) et 1862 (fiche n. 62), un «trait sur papier» en 1853 (fiche n. 57), auxquels il faut ajouter une lithographie réalisée en 1851 d'après l'huile de 1843.

6 À la fin de son ouvrage, Philippe Desan donne aussi une «Chronologie des œuvres. Peintures, dessins, gravures, lithographies, sculptures, monuments, objets \& médailles» (pp. 331-338), chronologie qui se révèle extrêmement utile pour avoir une vue d'ensemble de cette immense production iconographique concernant Montaigne. Desan ajoute en annexe un «Lexique des termes techniques» (pp. 327-330) qui permet même aux non-spécialistes de s'orienter dans le domaine immense, compliqué, voire insidieux de la lexicographie d'art.

7 Comme nous le remarquons à partir de cette iconographie, les portraits nous donnent l'image d'un homme toujours différent: jeune ou vieux, officiel avec son collier de l'ordre de Saint-Michel ou en tenue de voyage, réel ou au moins vraisemblable ou dans des situations clairement imaginaires (telles Montaigne visitant le Tasse ou Montaigne sur son lit de mort). Il ne faut pas du tout s'étonner; le gentilhomme 'voyageur' dont Desan parle dans sa préface est justement l'image, l'iconographie de Montaigne qui 'voyage' à travers l'histoire de l'art le long des siècles. Puisque jamais avant, si l'on excepte de brefs articles, ne s'était-on intéressé de manière si exhaustive à l'iconographie de Montaigne, cette iconographie va constituer pour les décennies à venir un point de repère et un ouvrage de référence pour les spécialistes et pour les amateurs de Montaigne qui, malgré les images existant, seront appelés à ajouter leur propre image aux représentations de ce 'gentilhomme voyageur' à travers les siècles. 